\title{
Evaluation of 45 chemicals as chemosterilants in adult male quail (Coturnix coturnix)
}

\author{
E. W. Schafer, Jr, R. B. Brunton and N. F. Lockyer* \\ U.S. Fish and Wildlife Service, Wildlife Research Center, Building 16, Federal Center, \\ Denver, Colorado 80225, U.S.A.
}

Since 1972, the Denver Wildlife Research Center has maintained a screening programme in which coturnix quail are used in a search for compounds that affect reproduction in male birds (Schafer, Guarino \& Brunton, 1976). The laboratory programme, operating in conjunction with field studies on the biological and ecological aspects of red-winged blackbirds (Agelaius phoeniceus; Bray, Kennelly \& Guarino, 1975), is designed to find a safe and effective avian male chemosterilant that can be used to reduce bird damage in agricultural and urban areas. The present paper presents the results of the tests conducted between 1972 and 1974 with 45 compounds of known or suspected chemosterilant activity in birds or rodents.

\section{Methods}

Our quail were randomly bred and raised in our facilities from original stock (Random Line 926) obtained from the University of California at Davis. Adult males weighed 110-120 g and females 125$145 \mathrm{~g}$ on average.

The chemicals used were technical grade, and were either purchased or were obtained from the sources given in the footnotes to Table 1. For both $\mathrm{LD}_{50}$ and reproductive tests, they were administered by gavage with propylene glycol as the carrier.

For each candidate chemosterilant, the acute oral $\mathrm{LD}_{50}$ (7-day observation period) was determined in male or female birds by the method described by Schafer, Brunton \& De Grazio (1973). An initial determination of chemosterilant activity was made by treating groups of 7 breeding males with a single dose of the candidate substance at about $50 \%$ of its $\mathrm{LD}_{50}$ value. If excessive mortality of treated birds resulted, a lower treatment level was also run. Compounds producing sterility in breeding males were then tested on groups of 7 males in which testicular regression had been induced by manipulation of the photoperiod (Schafer et al., 1976).

All treated males were individually caged with untreated females of known fertility in a photoperiod of $18 \mathrm{hr}$ light $/ 24 \mathrm{hr}$, and the reproductive success of the pair was measured over a 35-day period. Since the duration of the spermatogenic cycle in quail is probably between 20 and 25 days (Jones, Kominkova \& Jackson, 1972; Jones \& Jackson, 1972; Schafer et al., 1976), eggs produced after 20 days should reflect the effects of candidate chemosterilants on the initial phases of sperm development. Males were considered to be permanently sterilized if they showed sterility between 20 and 35 days after treatment (breeding males) or failed to become fertile between 20 and 35 days (quiescent males).

Eggs were collected three times during each 7-day period, incubated by weekly groups for 4 days, and then opened and examined for embryonic development. Individual eggs were classified as fertile, infertile or cracked (cracked eggs were not used in fertility computations). At the end of the 35-day period, males were killed with $\mathrm{CO}_{2}$, and both testes were extracted and weighed together.

Testicular weights were compared by one-way analysis of variance, and egg fertility data were arc-sine transformed and assessed by two-way analysis of variance with repeated measures (Winer, 1971). For both analyses, means were separated by Duncan's multiple-range test, with $P<0.01$ as the criterion of significance.

* Present address: P.O. Box 35, Saugatuck, Michigan 49453, U.S.A. 


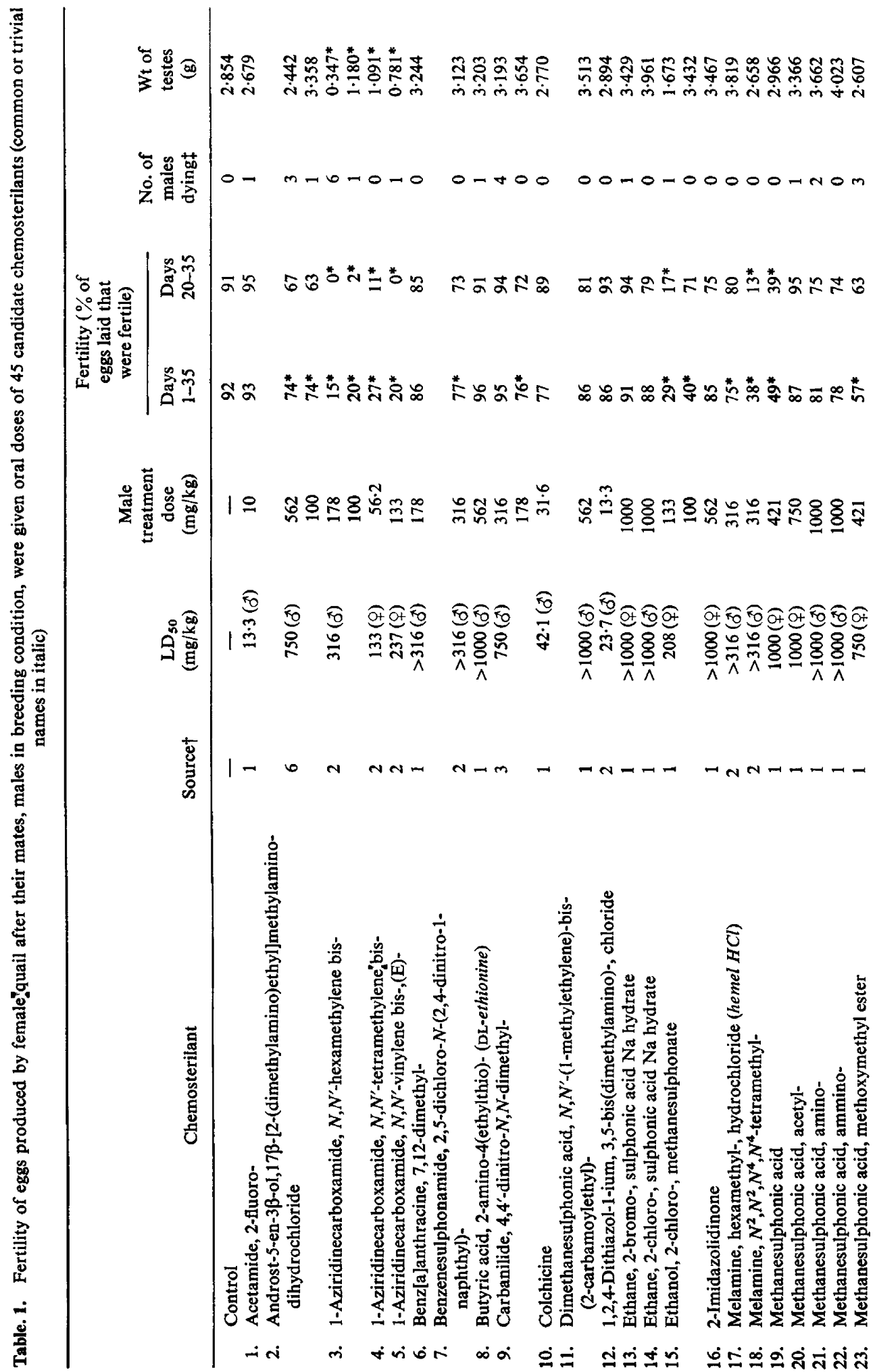




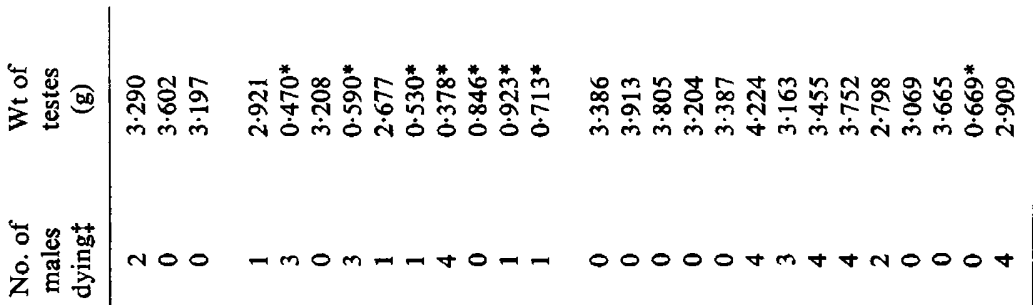

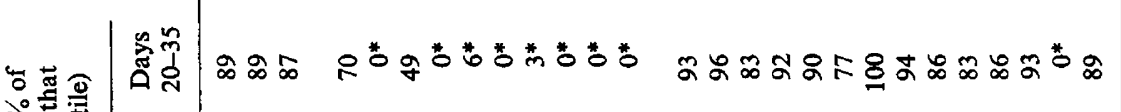

윰ำ

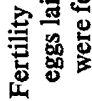

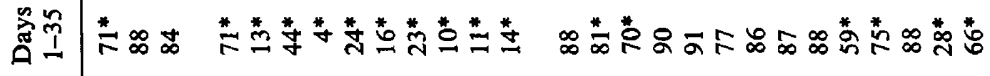

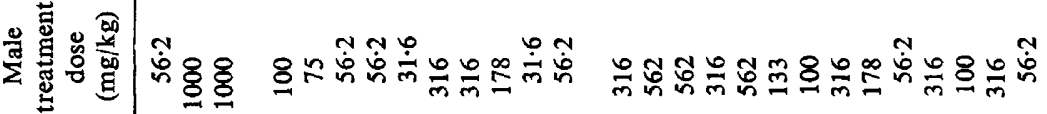

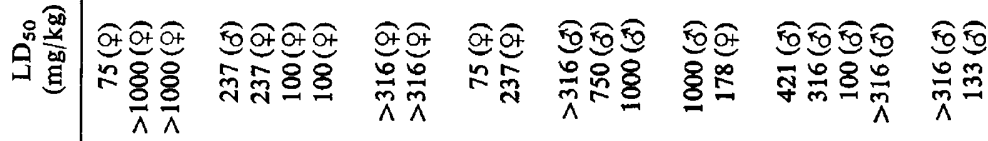

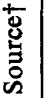

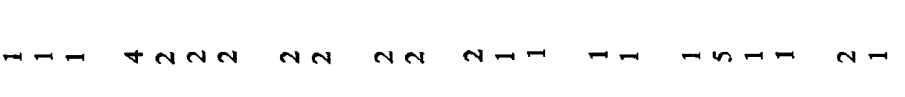

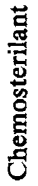

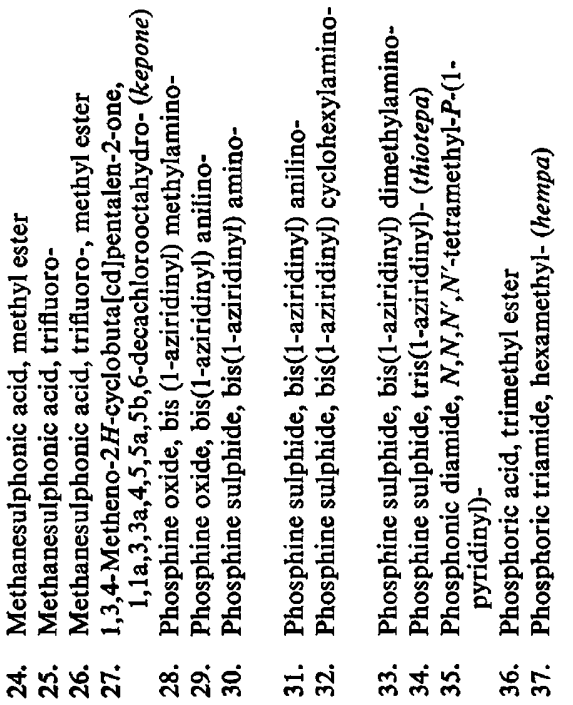

$\frac{1}{8}$

究\&

○.

$\therefore$

幽

웅

空。

$\ddot{\circ}$.

宛

矛

ठำ

욤

$\approx 0$

है

苋总

的

要

苓

节.

密

宅

हैं

를

웡

ठั.

娄

$+$

$\dot{a}$

V/ 突兽

V/

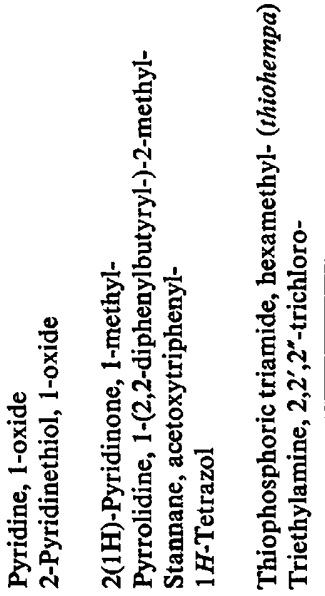

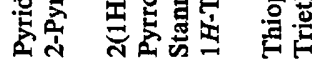

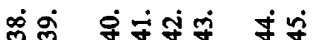


E. W. Schafer, Jr et al.

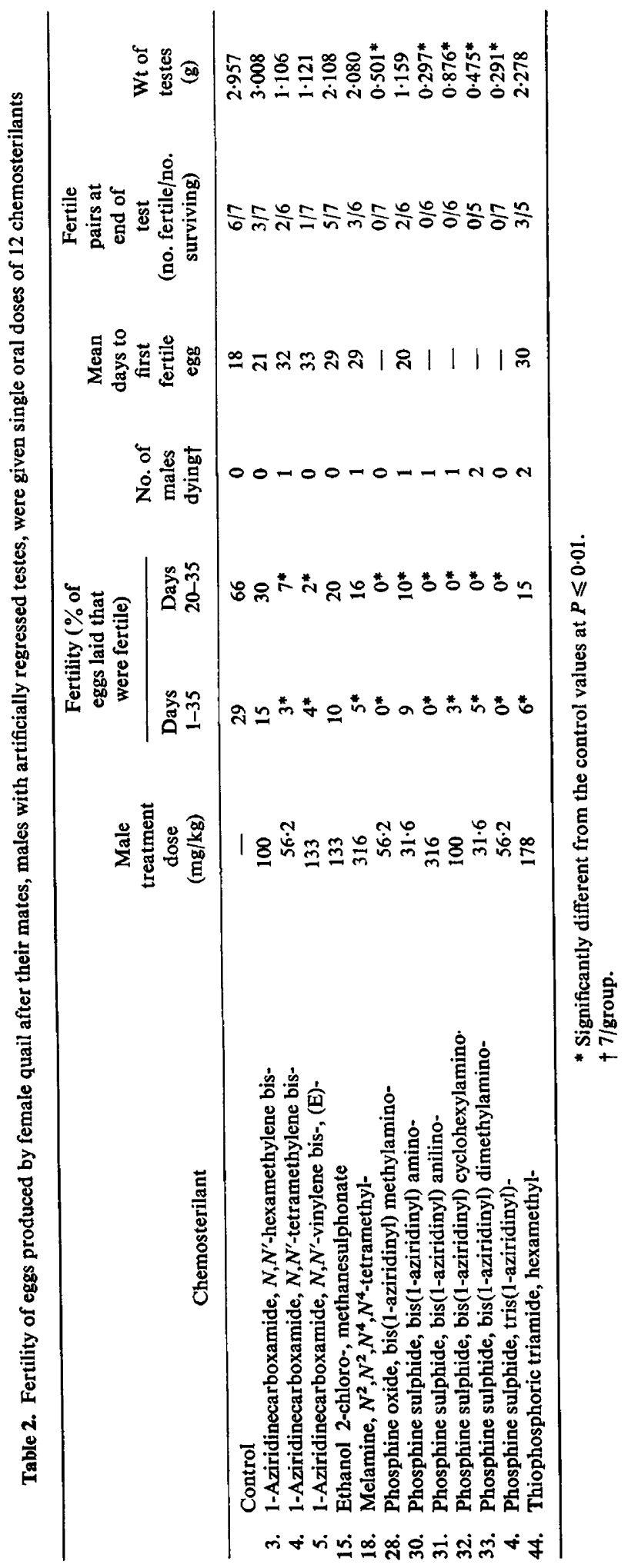


Additional details of the test procedures and environmental conditions are given by Schafer $e$ t al. (1976).

\section{Results}

Of the 45 compounds tested in breeding males, 13 resulted in significantly reduced fertility or sterility (Table 1). Of these active compounds, 6 were substituted bis(1-aziridinyl) phosphide sulphides or oxides, and 3 were substituted bis(1-aziridinecarboxamides). The combined testicular weights of the birds treated with 9 of the 13 compounds were less than $1 \mathrm{~g}$ at the end of the 35-day test period, compared with an average weight of $2.854 \mathrm{~g}$ for the controls.

When the 12 compounds that reduced fertility in the breeding males by at least $70 \%$ were tested in males with regressed testes (Table 2), 3 resulted in reduced fertility and 5 resulted in complete sterility. These five, all of which were substituted (1-aziridinyl) phosphines, also significantly reduced testicular weights and were considered to be the most effective in producing sterility under the conditions of our test. Studies are now being conducted with thiotepa, the most active of the five, on male starlings (Sturnus vulgaris), red-winged blackbirds, and female quail to broaden our knowledge of the chemosterilant activity of this compound under a variety of test conditions.

\section{References}

Bray, O.E., KenNelly, J.J. \& Guarino, J.L. (1975) Fertility of eggs produced on territories of vasectomized red-winged blackbirds. Wilson Bull. 87, 187195.

JONES, P. \& JACKSON, H. (1972) Estimation of the duration of spermatogenesis in Japanese quail using antispermatogonial chemicals. J. Reprod. Fert. 31, 319-322.

Jones, P., Kominkova, E. \& Jackson, H. (1972) Effects of antifertility substances on male Japanese quail. J. Reprod. Fert. 29, 71-78.
Schafer, E.W., JR, Brunton, R.B. \& De Grazio, J.W. (1973) Comparative toxicity of 17 pesticides to the quelea, house sparrow, and red-winged blackbird. Toxic. appl. Pharmac. 26, 154-157.

Schafer, E.W., JR, Guarino, J.L. \& Brunton, R.B. (1976) Use of the male coturnix in the laboratory development of avian chemosterilants. In Test Methods for Vertebrate Pest Control and Management Materials, American Society for Testing and Materials, Philadelphia (in press).

WINER, B.J. (1971) Statistical Principles in Experimental Design, 2nd edn. McGraw-Hill, New York.

Received 8 April 1976 